Voix plurielles 10.1 (2013)

\title{
Le cinéma identitaire franco-ontarien : un cas de figure de la fatigue culturelle ${ }^{1}$
}

\author{
Serge Miville, Université York, Canada
}

\section{Introduction}

Les études sur le cinéma franco-ontarien sont peu nombreuses ; outre les articles parus dans la revue Liaison (Truax ; Jaubert ; Larivière, «Quand on aime le cinéma », 1994) et au tour d'horizon de la cinématographie francophone hors Québec que propose Jean-Claude Jaubert dans le collectif Toutes les photos finissent-elles par se ressembler? (1999), les chercheurs se sont peu intéressés à ce chantier. En effet, un seul texte savant est paru sous la plume de Lucie Hotte, qui propose une lecture comparée du recueil Le Dernier des Franco-Ontariens de Pierre Albert et du film éponyme de Jean Marc Larivière et Marie Cadieux. Pourtant, le cinéma professionnel existe en Ontario français depuis plus de quarante ans. Les productions cinématographiques sont variées et relativement nombreuses. Afin de pallier l'absence d'analyse savante, ce texte analyse quatre cuvres documentaires du septième art traitant de la problématique identitaire franco-ontarienne, soit une par décennie depuis les années soixantedix. Les films retenus sont J'ai besoin d'un nom de Paul Lapointe (1978), Deux voix, comme en écho de Claudette Jaiko (1987), Le Dernier des Franco-Ontariens de Jean Marc Larivière (1996) et Pis nous autres dans tout ça? d'Andréanne Germain (2007).

La question identitaire est demeurée une problématique importante au cours des dernières décennies en Ontario français. C'est le lot de toute minorité de s'interroger sur son être et sur son devenir. L'élite franco-ontarienne a longuement lutté pour une reconnaissance de leurs droits (juridique ou «implicite » en tant que «peuple fondateur»), refusant de former une minorité comme les autres. Comme l'affirme Joseph Yvon Thériault, les francophonies minoritaires auraient un rapport fort à l'histoire, nommément l'histoire canadienne-française (« Entre la nation »). Ce rapport à l'histoire, que Fernand Dumont nomme la référence, rendrait légitime, selon ses ténors, la présence et le développement de ce groupe. De fait, ces minorités résistent à l'acculturation et à l'ethnicisation, et revendiquent un espace autonome tant pour la création que pour l'exercice de pouvoir légitime. Alors que le Québec, investi d'un État sur son territoire, est

en mesure de se concevoir en société autonome - ou quasi autonome -, l'Ontario français ne peut avoir une telle prétention. Pris entre la nation et l'ethnie, les Franco-Ontariens composent un 
«groupe nationalitaire» (Thériault, «Entre la nation», 22). L'ambivalence du «groupe nationalitaire »s'apparente aux mêmes difficultés que le Canadien français happé de « la fatigue culturelle » qu'Hubert Aquin a conceptualisé durant les années soixante.

À notre avis, il existe un certain nombre d'œuvres cinématographiques francoontariennes qui correspond à ce qu'Aquin nomme « la fatigue culturelle », caractérisée par une valse-hésitation entre l'intégration à la société dominante (dans le cas ci-présent, la culture anglo-américaine/canadienne) et la résistance à celle-ci. Cette tension serait cyclique et refait surface périodiquement. Sa réapparition mène le groupe au bord du précipice et chaque cycle peut provoquer l'effondrement au profit de l'assimilation à la « société globale » - ou dominante - à laquelle elle fait face.

Nous cherchons surtout à souligner la tension latente entre la résistance à l'acculturation et la folklorisation de la culture canadienne-française/franco-ontarienne devant la culture dominante anglo-canadienne qui se manifeste dans le cinéma identitaire franco-ontarien. Bien que l'Ontario français ne puisse espérer former une nation ou une société à part entière, son réseau d'institutions, son espace politique et son rapport à l'histoire montrent son intention de «faire société », de sorte que le cinéma franco-ontarien devient un cas de figure intéressant pour s'interroger sur la « fatigue culturelle ».

Dans son texte publié en 1962, Aquin souligne l'existence d'un cycle engagé depuis belle lurette. Lors de moments forts, la culture minoritaire, vive, affirme sa légitimité. À d'autres moments, elle se fragilise. De plus, chaque période d'affaissement court le risque de l'abdication de l'individu, d'un « dépaysement intérieur » aux dires de Daniel Jacques (2). La tension est d'autant plus forte qu'en raison d'une conviction des ténors de la modernité, la culture canadienne-française empêcherait d'atteindre l'universalisme qu'offre, par exemple, la culture anglo-américaine :

Le Canada français, culture fatiguée et lasse, traverse depuis longtemps un hiver interminable; chaque fois que le soleil perce le toit de nuages qui lui tient lieu de ciel, ce malade affaibli et désabusé se met à espérer de nouveau le printemps. La culture canadienne-française, longtemps agonisante, renaît souvent, puis agonise de nouveau et vit ainsi une existence faite de sursauts et d'affaissements (Aquin 227).

Minoritaire sur son territoire, le Franco-Ontarien ne peut jamais espérer atteindre une « globalité », n'ayant pas les leviers d'un État. Différent du Québecois, il fait néanmoins face à 
des pressions similaires. Assujettis à la tentation «d'être grand» comme dirait Thériault, l'Ontario français risque facilement de renoncer à son comportement nationalitaire (ou à sa résistance) au profit d'une acculturation à la société dominante, à l'instar des nombreuses cultures immigrantes au pays. C'est dans cette optique que le cinéma d'auteur franco-ontarien exprime le véritable déchirement que vivent les francophones de l'Ontario.

\section{Le conflit élite/jeunesse ou un « moment fort » du militantisme franco-ontarien}

Dans son long métrage documentaire, J'ai besoin d'un nom $(1978)^{2}$, tourné au milieu des années soixante-dix, Paul Lapointe nous mène au cœur d'un conflit générationnel entre FrancoOntariens et illustre un «moment fort» du militantisme franco-ontarien. Les dichotomies entre la «vieille garde» et la jeunesse, la ville et la campagne, l'Église et la discothèque et le modernisme et le traditionalisme nous rappellent les clichés qui qualifient le Canada français comme une société renfermée qui, après les années soixante-dix, accepte enfin de se moderniser. La jeunesse, animée par la contre-culture, ne trouve plus son compte dans l'Association canadienne-française de l'Ontario (ACFO) et dans la société canadienne-française qui ne se serait pas encore actualisée. La contre-culture en Ontario français est un phénomène puissant qui ébranle les vieilles structures et provoque un passage de la «tradition » à la «participation » (voir Bock). Malgré la contestation, le film de Lapointe nous montre une jeunesse engagée sur l'identité franco-ontarienne.

La problématique de l'impact de la culture «dominante » est abordée d'emblée dans le film lorsqu'un anglophone affirme que «[t]here are 250 [million] American English-speaking people to the south of us beaming their television programmes into the southern parts of this province and all across Canada where [most of] the population lives. There is just no hope [pour la culture canadienne et canadienne-française de percer chez elle]». Le destin, qui semble sombre pour le Canada, est, par extension, encore plus pessimiste pour les Canadiens français. Lapointe présente ensuite l'historien québécois néonationaliste Michel Brunet. Celui-ci déclare qu'il «l'[a] dit depuis longtemps que [, pour] les minorités francophones hors Québec, quant à [lui], il n’y a pas d'avenir ». Selon Brunet, «[1]e débat a commencé dans la vallée du SaintLaurent, et il finira là ».

Dans le film, la jeunesse franco-ontarienne est tiraillée entre sa perception d'un Canada français ancien et «prémoderne » et le monde anglo-américain dans lequel elle baigne ; elle est 
déchirée entre sa «fatigue » d'être petit et son désir « d'être grand », pour reprendre Thériault. Lapointe fixe son objectif sur une pièce du Théâtre de la Corvée de Vanier dans laquelle cette problématique est clairement illustrée. En évaluant les divertissements du village, la troupe énumère « $[\mathrm{d}]$ es parties de hockey, les danses $[\ldots]$, les stags $[\ldots]$ des comptoirs à la SaintVincent-de-Paul, des mariages, des baptêmes, des enterrements pis bien des affaires !». Cette programmation ne semble pas convaincre tous les comédiens. Une en particulière, cherchant des sensations plus fortes, affirme « [q]u'est-ce que je voudrais là, ben, ben, c'est de l'action! Tsélà ? De l'action ! » La vie «traditionnelle » canadienne-française n’offrirait pas cette possibilité. Le réalisateur coupe et se tourne vers le centre-ville de Toronto où l'on peut apercevoir des bars de danseuses nues sur le fond d'une musique disco. La comédienne renchérit : «C'est ça qui [nous] manque icitte. Tsé, une fille qui veut faire son chemin, j'te dis qu'elle trouve les trottoirs pas mal étroits ». Pour être grand, mieux vaut la métropole anglophone, légitime, que le village francophone voué à la médiocrité.

La dichotomie entre la modernité et la tradition est aussi incarnée lors du congrès de l'ACFO à Sudbury en 1976 sous forme de conflit entre générations. Lapointe nous montre une ACFO difficilement renouvelée. Un commentateur affirme qu'un fossé s'est creusé entre une élite renfermée et les Franco-Ontariens :

What has happened in the French Canadian community in Ontario is that there has been an elite that developped that really is not responsive and has never taken time to go back to find out what the needs are of the French Canadian population. And I think that the anglophones in Ontario view that elite as being very powerful [...] and also very small and that's why there is a great deal of confrontation in Ontario.

De son côté, l'historien Gaétan Gervais indique dans le film que l'économie n'a pris une importance à l'ACFO qu'après de maintes pressions exercées par certains congressistes. Sur cette question, il affirme qu'il «y a des résistances très considérables », car « [o]n est obsédés par des questions de culture et de loisir ». D’autre part, une jeune déléguée déclare que

l'ACFO donne une image d'une organisation d'un club d'âge d'or, d'un paquet de vieilles mémères qui [ne font] absolument rien. [Ce ne sont que des] bonnes sœurs à la retraite pis absolument rien [... ne] se produit, il n'y a rien qui arrive [... et] [1]es gens [sont] d'une étroitesse d'esprit phénoménale [...] dans la plupart des ateliers [et] [d]es discussions [et je crois que] la majorité des gens de l'ACFO font preuve d'une masturbation intellectuelle extraordinaire. 
L'intention du réalisateur n'est pas de simplement montrer l'impuissance relative des Franco-Ontariens ou de l'ACFO. Son jeu de dichotomies tente de convaincre l'auditeur du tournant vers la modernité des Franco-Ontariens. La jeunesse est porteuse non seulement d'un discours antiélitiste contre la «vieille garde », mais d'une quête identitaire et d'un renouveau dans le militantisme. Toutefois, notons que le projet que défendent ces jeunes, demeure nébuleux. Lors du banquet du congrès, une troupe de théâtre met en scène une procession de foi avec plusieurs comédiens munis de cagoules et brandissant un drapeau franco-ontarien. Ceux-ci adoptent un trajet qui les mène à diverses stations thématiques (santé, économie, culture, etc.). Le comédien maître de cérémonie tient une procession et commente chaque station. Enfin, il entame un dialogue avec les autres comédiens :

-J'ai besoin d'un nom.

-Sudbury!

-Un autre!

-Sudbury !

-Un nom propre!

Rires dans la salle.

La quête du nom pour remplacer ce Canada français désuet donne autant les marques d'une critique de l'élite que d'un désir de réinvestir son milieu culturel, et montre fort bien la portée de la « fatigue ».

Dans une scène remarquable, Lapointe montre Lise Pellerin et Raymond Lalonde à une station de radio à Sudbury dans laquelle ces deux discutent de leur militantisme et de leurs points de vue sur la question identitaire en Ontario français. Pellerin écope d'une peine de prison après avoir refusé de renouveler son permis de conduire en anglais et revendiqué un procès en français à la cour de l'Ontario. De son côté, Lalonde a organisé une manifestation pour appuyer cette dernière. Il en profite pour poser un diagnostic, propre à l'être «fatigué », lorsqu'il prétend que les Franco-Ontariens ne seraient pas fiers d'être « français ». Il déclare d'ailleurs que « la plupart des Franco-Ontariens ne se rendent vraiment pas compte qu'ils sont premièrement [...] Canadiens f]rançais et deuxièmement qu'ils sont Canadiens ».

La tension entre deux sociétés - canadienne-française et canadienne - est abordée comme sous-thème au conflit entre l'élite et la jeunesse franco-ontarienne. Bien que le film nous montre un «moment fort » d'affirmation et de militantisme dans cette remise en question de la vieille garde, soulignons qu'aucun projet tangible n'émerge chez cette jeunesse militante, contrairement 
au projet sociétal canadien-français. Il semble bel et bien y avoir un désir de vivre pleinement sa culture, mais celle-ci évolue sous une forte pression des cultures dominantes. Bref, si l'Ontario français existe, c'est par rapport au Canada et à l'Ontario anglophone majoritaires, et non pas en tant que culture autonome.

\section{Le creux de la vague : la fatigue culturelle dans le cinéma franco-ontarien}

La fatigue individuelle chez Claudette Jaiko

Les années quatre-vingts et quatre-vingt-dix font figure de creux de vague alors que la fatigue culturelle est la plus présente dans les films identitaires franco-ontariens si l'on s'en tient aux deux films à l'étude pour cette période. L'échec du référendum sur la souveraineté du Québec de 1980 est suivi de réformes constitutionnelles dans lesquelles les francophones ne trouvent pas nécessairement leur compte. Les tentatives à amender la Constitution échouent en 1990 avec l'Accord du lac Meech et de nouveau en 1992 avec l'Accord de Charlottetown. Cela engage notamment un mouvement de contestation dans l'Ouest avec la formation du Parti réformiste en 1987, la création du Bloc québécois en politique fédérale en 1991 et la victoire du Parti québécois avec un programme souverainiste en 1994. S'ensuit un nouveau référendum que le OUI perd in extremis en 1995. Bref, le pays est sous le choc et l'unité nationale n'est pas garantie. Le cinéma franco-ontarien navigue en eaux troubles, provoquant de profondes réflexions sur son être et sur son avenir.

Nous analyserons la «fatigue » à partir de Deux voix, comme en écho, un court métrage documentaire de Claudette Jaiko (1987), et Le Dernier des Franco-Ontariens de Jean-Marc Larivière, un docu-fiction produit en 1996. Dans le premier cas, la fatigue culturelle est individuelle; elle ronge la cinéaste et son frère et mène ce dernier vers l'assimilation. Dans le second, c'est la collectivité franco-ontarienne dans son ensemble qui vit l'épreuve.

Véritable documentaire d'auteure et autobiographique, Deux voix, comme en écho témoigne de la lourdeur de la fatigue culturelle chez l'individu. Jaiko relate les mêmes dichotomies que Lapointe - celles de la ruralité et l'urbanisme, de la tradition et de la modernité -, mais sous l'angle d'un monde de sens à un monde éclaté à partir duquel se joue la survie culturelle et linguistique du Franco-Ontarien. Jaiko y juxtapose son expérience afin de redécouvrir sa francité comme marqueur identitaire et culturel légitime, mais toujours fragile. L'expérience de son frère Alain sert de contrepoids à celle de Jaiko. Celui-ci a choisi de rejeter la 
langue française qu'il juge trop contraignante - pour ne pas dire «petite » - et croit qu'elle n'a que peu d'utilité dans le monde dans lequel il souhaite évoluer, celui des « grands ». Le film met en scène deux personnages atteints de fatigue culturelle. Alors que Jaiko s'en sort convaincue, mais fragilisée, son frère Alain trouve un sens à sa vie en anglais. Alors qu'elle renaît, affaiblie, lui s'assimile.

Tout au long du film, Jaiko est à la recherche d'un sens dans un monde éclaté. Elle semble le retrouver dans le français : «Mes rêves et mes souvenirs sont en français. Cette langue m'habite, me parle. S'il m'arrivait un jour de ne plus le parler, s'il m'arrivait un jour [de] ne plus l'entendre, j'ai l'impression que moi-même je ne serais plus qu'un rêve, qu'un souvenir » ${ }^{3}$. Jaiko n'est que partiellement satisfaite de voir dans le français un ancrage identitaire. Elle est déterminée à recruter son frère dans le but de trouver le plein sens à son identité, mais elle est vite frustrée :

-Alain, je n'entends plus ta voix. Dis-moi quelque chose en français.

-I can't.

-Tu ne veux pas?

-No, it's not that. I don't even remember speaking it.

Alain n'a pas seulement oublié comment parler français, mais il considère cette langue comme un facteur d'exclusion, d'empêchement. Elle aurait fait en sorte qu'il soit un étranger dans la société tout comme son père, immigrant ukrainien : «Dad always knew what it was like being a stranger. His own parents were Ukranian and settled in France when he was still very young. Like us, he had to deal with two languages, one at home and one at the outside ». La tension remonte depuis très longtemps pour le frère de Jaiko. Mobilisant la mémoire de son père, il indique avoir beaucoup en commun avec lui : «He once told me he never felt comfortable expressing himself in his mother tongue. Just as I have never felt at ease in mine. [... It sounds f]amiliar, and foreign at the same time ». Jaiko lui répond que le français n'est pas une langue étrangère. Alain réplique qu'entre lui et ses amis, elle l'était. Il en déduit qu'elle faisait partie d'une «hidden culture », une culture refoulée. Sa sœur, convaincue que le français est la clef nécessaire à sa compréhension d'elle-même, rétorque : «Tu te caches Alain, je le sais, tu le sais ». Alain, selon Jaiko, nie son identité, l'ayant troquée pour une autre.

Le choix d'Alain pour cette acculturation relève de deux grands facteurs. Le premier est la honte, élément emblématique de la fatigue culturelle, ce qui mène inexorablement à son 
assimilation. Le français nuisait à son intégration dans le monde des «grands ». Lorsqu'il était enfant : «I used to get teased about my French accent. So I lost it and spoke like everybody else. By the time I was 8 or 9 I was thinking only in English. French had become a struggle. I felt so inadequate. That's when I decided that if I couldn't speak it well enough, I wouldn't even try ».

Alors que sa mère proposait à lui et à Jaiko des exercices de français après les heures d'école pour perfectionner la langue, Alain contestait, non pas pour se rebeller, mais parce qu'il «felt self conscious and false when I used [le français] out of a sence of duty». Pourquoi s'efforcer d'utiliser cet idiome par devoir lorsque le monde de l'extérieur se déroule en anglais ? C'est dans cette langue qu'Alain cherche son salut.

Le second facteur déterminant qui pousse la fatigue d'Alain à son comble, est l'incapacité de la langue française à lui garantir l'avenir qu'il souhaite : «I felt like they [ses parents] were trying to hold me back, preventing me from growing up. I knew [that] they were fighting a losing battle. Maybe they did too. Already I could see that French wouldn't be important for me. I didn't have to decide. English was going to be the language of my world, the business world I wanted to live in ».

Lorsqu'Aquin écrit en 1962 qu' «[u]n jour, nous sortirons de cette lutte, vainqueur ou vaincus » (277), il fait référence à la lutte de l'individu et de la collectivité pour sa légitimité en tant que société, à une lutte entre l'intégration à la culture dominante et la résistance du plus petit. Alain s'avoue vaincu, sans que ce soit une tragédie pour lui. En adoptant la société des « grands », la société anglophone, il parvient à vivre comme bon lui semble, ce que le français ne lui permettait pas. L'assimilation pour Alain n'est pas un drame, mais un affranchissement devant un esclavage culturel et linguistique. Le succès matériel et la normalité se trouvent pour lui dans la vie en anglais et à Toronto. Le français n'était pour Alain qu'un carcan; sa culture l'avait empêché de croître et de réussir.

Or, pour l'observatrice, sa sœur, cette libération n'est rien d'autre qu'un véritable désastre : «Moi aussi je me suis éloignée de Lafontaine. Moi aussi j’ai voulu m'intégrer à ce monde cohérent, homogène, à ce monde d'adultes qui ne parle qu'une seule langue. Mais je n'ai jamais réussi à faire taire en moi cette autre langue. J'avais même honte de l'oublier si rapidement ». Le passage du français à l'anglais de son frère la rend perplexe :

Je n'arrive pas à comprendre comment Alain peut se sentir si détaché. Comment il peut être si imperturbable ? N'est-il pas aussi issu de la même réalité que moi ? 
N'est-il pas lui aussi habité par la même inquiétude ? N'avons-nous pas eu la même enfance? N'est-il pas encore mon frère ? Je ne lui reproche pas d'être devenu ce qu'il est, mais de me laisser pour ainsi dire seule à la recherche de cette partie de moi-même qu'il nie et dont il partage pourtant le secret.

Ces questions ne se posaient pas chez les générations passées. Selon Jaiko, « Mes grandsparents, leur vie avait un sens [... et ils] trouvaient [...] un équilibre qui me fait défaut ». Cette petite société dans laquelle vivaient ses ancêtres, avait un sens qui lui échappe. Ressentant le désespoir, elle tente de s'agripper à son frère pour qu'il la rassure : «Alain, dis-moi que tout ceci existe, que tu n'as rien oublié ». Son frère lui offre une réponse peu consolatrice : «[y]ou're not gonna find what you want from me. I am who I am. We're different. We're no longer children. You have to understand that ».

Cette fatigue individuelle peut trouver son issue de deux façons. La première, la voie choisie par Alain, est une acculturation envers la culture dominante anglo-américaine. Elle ne demande aucune résistance. En effet, selon Aquin, ce serait «beaucoup plus reposant de cesser d'exister en tant que culture spécifique; et de vendre une fois pour toutes notre âme au Canada anglais [...] » (218). L'autre chemin est celui de la quête identitaire et du combat perpétuel qui emporte avec elle d'autres épisodes de fatigue culturelle, c'est-à-dire la fragilité en perpétuité. Cette voie semble être celle que souhaite emprunter Jaiko, bien qu'elle soit fragilisée par l'épreuve.

\section{La fatigue collective chez Jean-Marc Larivière}

La fatigue culturelle est un phénomène collectif dans le docu-fiction Le Dernier des Franco-Ontariens de Jean Marc Larivière ${ }^{4}$. Ce film basé sur le recueil de poésie du même nom de Pierre Albert met en scène le malaise du Franco-Ontarien minoritaire dans l'univers anglophone. Le côté fictif est assuré par de nombreuses personnalités ayant elles-mêmes conçu leur texte, notamment le Spectre (Marcel Aymar), Nino le clown (Roch Castonguay), la femme du Dernier des Franco-Ontariens (Paulette Gagnon), Robert Dickson, Patrice Desbiens et Robert Marinier, ainsi que Pierre Albert et plusieurs intellectuels, dont Pierre-Raphaël Pelletier et François Paré, pour les éléments documentaires du film.

Albert postule la fuite en avant du Franco-Ontarien dès le début du film, la qualifiant de résistance aux questions identitaires interminables. Albert ne se contente pas de la société angloaméricaine, mais bien du monde entier : «Vous comprenez, moi, que le problème francoontarien, je suis bien au-dessus de tout ça. Moi, vous voyez, je suis un citoyen du monde ». C'est 
pourquoi il tente d'organiser un «dernier show » pour souligner la fin des Franco-Ontariens. Il déclare d'ailleurs que «[1]e Dernier des Franco-Ontariens sait qu'on ne naît jamais francoontarien. Tout ce qu'il sait, c'est qu'on peut mourir franco-ontarien. Et qu'entre la naissance et la mort, il y a le doute ». Ce doute, ou fragilité, « [est] un diable bienfaisant», affirme le Spectre. En effet, il permet l'affranchissement du Franco-Ontarien avec sa mort et sa renaissance dans la culture du majoritaire. Toutefois, le doute peut aussi amener le Franco-Ontarien à sa propre plénitude pour Pierre-Raphaël Pelletier :

Le Dernier des Franco-Ontariens [...] se rend compte qu'il n'a plus de prise sur rien $[\ldots$ et qu'] il y a [...] une espèce de doute qui commence à être très corrosif. Puis il continue à croire qu'il écrit tout croche ou il essaie de rattraper l'écriture qui est pleine de trous, puis tout à coup, il revient sur la certitude [qu'il] est peutêtre rien, puis le rien vaut cette certitude. C'est un maudit lot à porter. [... Ce] mélange[-]là d'ambiguïtés, de paradoxes de contradictions [...] sont dans le fond les composantes d'un minoritaire, de quelqu'un qui se sent qu'il n'est pas là parce qu'il [y] a une autre [...] majorité qui envahit un espace [qu'il croyait être le sien] où finalement il est [à] faire un autre espace [...] qui est le vide [...] ou est-ce que c'est un espace qui va me faire éclater [... et] qui va me permettre de surgir dans un niveau imaginaire, dans une structure qui pourrait faire en sorte que je sens que le doute m'a finalement catapulté vers quelque chose de plus solide que le doute ?

La problématique sociétale est toutefois très complexe. Albert nous explique qu'il existe au pays deux sociétés (le Canada et le Québec) et que le Franco-Ontarien est un simple fragment qui peut espérer se greffer à l'un ou à l'autre : «le Dernier des Franco-Ontariens a sérieusement pensé déménager au Québec. À immigrer au Québec. Il savait qu'il ne pouvait pas y rester franco-ontarien. Il [n'] avait pas le goût de s'assimiler au Québec ». Pour Albert, il serait impossible d'être lui-même au Québec.

Dénudé de sens, le Franco-Ontarien semble voué soit au néant, soit à l'acculturation. En fait, c'est ce qui se produit dans la scène de Nino le clown. Ce dernier joue avec le mot «Ontarien » lorsqu'il tente d'écrire un envoi postal en guise d'invitation au « dernier show»: «On-ta-rien. Rien ? Ontarien ? Non [...]. Roi ? Oui ! Oui ! Onta-roi. Roi. Ontarois. [... N]on. [...] Onta-ici. Ici. Venzez [sic ...] au dernier show. Les deux ponts. Fau-kyé. [...] Fuck hier. » Après avoir terminé la lettre, il la met dans une enveloppe et l'insère dans une boîte aux lettres, après quoi il attend un moment, aperçoit le pli et s'exclame «[c]'est pour moi ! ». L'artiste est aussi public, preuve d'une société trop petite.

Lorsque François Paré et Pierre Albert discutent à Sudbury, Paré dit à Albert que son 
recueil de poésie touche au nerf de la guerre des Franco-Ontariens; ce serait «une culture qui s'est définie par sa propre catastrophe finale ». Alors que les Acadiens ont vécu le Grand dérangement et les Québécois la Conquête, Paré croit que, pour les Franco-Ontariens, «notre catastrophe $[\ldots]$ s'en vient ». Enfin, cette culture franco-ontarienne est si fragile qu'elle risque de s'évanouir sans que l'on y porte attention. Selon lui, cette culture «pourrait disparaître dans l'indifférence totale ».

Pelletier, dans une autre scène, conteste le postulat d'Albert : «Quelle stupidité de penser que d'être moins grand en nombre influe sur la qualité de ce que peut être cette différence du nombre ». Pour Pelletier, la petite culture peut être aussi légitime que celles des « grands ». Son particularisme ne serait pas contraire à la modernité. Le « doute » du Franco-Ontarien «peut être [...] corrosif, mais [... il] peut être aussi une mutation vers une plénitude d'une réalité qu'on crée constamment par-devant soi ».

Malgré cette lueur d'espoir, Robert Marinier, l'homme aux diapositives, présente un monologue satirique sur sa vie culturelle franco-ontarienne qui contraste avec l'affirmation de Pelletier. Marinier joue un Franco-Ontarien épanoui du point de vue matériel avec ses «trois télés couleur, deux VCR [et] la TV payante [... comme quoi il aurait] tout ce qu'il faut pour être heureux. L'amour et le câble », mais qui se plaint. La plainte du Franco-Ontarien détermine ce qu'il est : «je me plains, donc je suis ». Toutefois, Marinier tient un double discours. Alors qu'il se lamente, il décrit une existence de gaieté et d'assurance :

Contrairement aux jumelles Dionne, les cinq martyres franco-ontariennes, j'ai eu une enfance heureuse. [Je n'ai] pas été privé de quoi que ce soit. Mes parents [ne] m'ont pas battu, abandonné ou causé plus de cicatrices émotionnelles qu'il [ne le] fallait. Aujourd'hui, je suis capable de maintenir des relations saines et heureuses. Je transmets à mes enfants les mêmes valeurs que j'ai reçues de mes parents [...]. On [ne] crève pas de faim [... 1] e frigidaire est toujours plein. Le congélateur aussi [...] chez nous, on mange santé. Le frigidaire est plein, donc je suis.

Cette sécurité matérielle dénature-t-elle le Franco-Ontarien ? Marinier s'interroge. Il a une «bonne job » qui lui permet de travailler «dans la langue officielle de [son] choix », il gagne un bon salaire, il est à l'abri des fermetures d'usines, il écoute CANO, participe au Festival franco-ontarien et sa femme siège à des conseils d'administration d'organismes culturels. Malgré ces conforts, il se plaint : «Tout va bien, donc je suis heureux. Mais je me ... Je [ne] peux pas vraiment me plaindre. Qui suis-je, alors? Je sens une crise d'identité qui 
approche ». En ce sens, il met le doigt sur ce qui afflige les «groupes nationalitaires ». La lutte pour la légitimité et contre la fragilité constante est une caractéristique fondamentale de la culture franco-ontarienne. Mais lorsqu'il n'y a plus de raisons de se plaindre ou de lutter, lorsque l'intégration à la société canadienne est complète, faut-il se «plain[dre] de [s]es doutes, ou douter de [s]es plaintes ? » Sans cette fragilité, le Franco-Ontarien est incapable d'être FrancoOntarien. Marinier, de son côté, heureux dans son confort matériel, prend sa décision : «Je doute, donc je suis. Okay. Ma crise d'identité est finie ». Le Franco-Ontarien est donc condamné à jamais à se plaindre de son chevauchement entre deux cultures.

Larivière tente dans son film de confronter les habitants du village de Fauquier avec ce choix. Albert invite différentes personnes de son village natal à participer à son dernier show en indiquant que c'est la fin des Franco-Ontariens. Les gens de Fauquier, perplexes devant les motivations d'Albert, refusent l'idée qu'il n'existera plus de Franco-Ontariens : «Y'en a pas de Dernier des Franco-Ontariens parce qu'y’en a encore ». Lorsqu'Albert demande à une dame si elle y sera, insistant qu'après le spectacle, il n'aura plus de show, elle lui répond par la négative, puisque «[ç]a fait trop longtemps qu'on se bat pour ça ». Dans la scène suivant le générique de la fin, une dame parle à un homme sous le pont de Fauquier avec, devant elle, une marmite sur le feu. Faisant allusion au sort des Franco-Ontariens, elle explique à l'homme que « si je mettais ma grenouille dans l'eau froide, et que je faisais tranquillement bouillir l'eau, la grenouille se laisserait ébouillanter vivante. Mais si je la plonge directement dans l'eau bouillante, elle saute, tout de suite, en dehors de la marmite ».

Le film de Larivière, vu dans l'optique de la fatigue culturelle, nous présente une culture à la croisée des chemins, en perpétuelle tension entre son désir de «faire société » et le désir d'être « grand». Il serait possible de se greffer à la globalité québécoise, mais ce serait, selon Albert, s'assimiler à un groupe qui, si l'on s'en tient à l'actualité constitutionnelle de l'époque, l'ignore. Comme la globalité en français semble être impossible à acquérir, un choix s'impose : continuer ou se livrer? La fatigue risque donc de consommer petit à petit le Franco-Ontarien sans qu'il ne s'en rende compte.

\section{Sortir du creuset : se réinscrire dans l’idée « canadienne-française »}

La fatigue culturelle se vit de façon cyclique. Durant les moments creux, le comportement nationalitaire est le plus faible, et le cinéma franco-ontarien illustre le danger de 
l'ethnicisation (et l'assimilation) du groupe. Toutefois, le nouveau millénaire semble avoir apporté une bouffée d'air frais chez une certaine jeunesse franco-ontarienne. En cherchant à combattre le vide identitaire qu'emporte l'Ontario français - trop petite pour être une nation, mais, ayant un fort rapport à l'histoire, elle refuse de s'afficher comme ethnie -, il est peu étonnant qu'une relève cinématographique s'intéresse de nouveau à la problématique identitaire. Ce qui surprend, c'est qu'elle se nourrit d'une certaine idée du Canada français afin de sortir du cul-de-sac identitaire. Pis nous autres dans tout ça? d'Andréanne Germain aborde une voie interprétative différente pour traiter de la question nationale en Ontario français.

La période de 1996 à 2007 n’est pas sans éclats pour la Francophonie canadienne. La crise de l'hôpital Montfort en 1997-2002 (voir Gratton) à Ottawa a été d'une importance singulière pour les francophonies canadiennes minoritaires, tout comme l'éclatement de l'ACFO et la fondation de l'AFO l'ont été pour l'Ontario français en 2006. La crise sur les accommodements raisonnables et sur l'identité québécoise (2007) est aussi révélatrice des tensions qui existent présentement dans les démocraties occidentales entre l'histoire, l'identité, la mémoire et l'intégration de nouveaux arrivants de cultures diverses. Bref, les pièces étaient en place pour un tel questionnement identitaire.

Dans le film de Germain, deux Québécois, Antoine et Nicholas, se joignent à la réalisatrice en brandissant d'énormes drapeaux franco-ontariens. Le groupe se rend sur les Plaines d'Abraham pour la Saint-Jean Baptiste. Les deux Québécois doivent prendre le rôle de Franco-Ontariens lors de la fête. Germain cherche à faire vivre l'expérience minoritaire à ceuxci.

Le début du film nous inscrit directement dans la problématique en montrant des extraits télévisés d'un débat à la Chambre des communes en novembre 2006 lorsque le gouvernement minoritaire conservateur de Stephen Harper adopte une motion reconnaissant les Québécois comme formant une nation dans un Canada uni. Si, historiquement, les Canadiens français étaient autrefois réunis au sein d'une même nation sur les plans linguistique, culturel, religieux et en tant que communauté de destin (voir Dumont), les cartes sont davantage brouillées avec l'adoption de cette motion au Parlement. Germain précise : «De nos jours, la nation québécoise a remplacé le concept du Canada français qui est maintenant réduit aux frontières du Québec ${ }^{5}$ », ce qui inspire sans doute le titre du film.

Germain, adoptant le style du cinéma direct, jongle avec l'idée de réinscrire le Franco- 
Ontarien dans le giron canadien-français et québécois, une idée qui semble presque impensable encore aujourd'hui. Elle va donc sur les Plaines pour discuter avec les fêtards au sujet de la Saint-Jean Baptiste, fête nationale des Canadiens français. Or, cette fête est, depuis 1977 au Québec, surnommée la « Fête nationale ».

Le film surprend par l'ouverture des Québécois interviewés à la problématique francoontarienne. Nicholas, un des participants, est étonné de voir un drapeau franco-ontarien. Croyant d'emblée que les Franco-Ontariens sont davantage Canadiens que des Canadiens français, il se « demandai[t] s['ils] allaient avoir des drapeaux canadiens ce soir à la Saint-Jean ». Satisfait que ce ne soit pas le cas, il s'avance pour dire que « le drapeau franco-ontarien, ça va par exemple ». L'épreuve mène à une certaine compréhension des difficultés d'être de la collectivité francoontarienne, déchirée entre deux sociétés. Vers la fin du film, Antoine réfléchit à son expérience et indique qu'il « n’envie pas cette position [de Franco-Ontarien... et que] ça devrait être très, très difficile », alors que Nicholas vise bien en proposant que « [c]'est être pris entre deux cultures ». Avouant l'impossibilité pour les Franco-Ontariens à s'intégrer à la nation québécoise, Germain admet néanmoins que, «dans le fonds, on veut la même chose, la préservation de la langue française en Amérique ». Demeurant candide quant aux difficultés structurelles qui se présentent devant un éventuel renouveau entre Québécois et francophonies minoritaires, elle croit malgré tout que « [1] e fait qu'on s'y prend différemment [pour préserver cette francophonie] ne veut pas dire pour autant qu'on est si différent que ça ». Différence, certes, mais la cinéaste, contrairement aux autres réalisateurs à l'étude, veut renouer avec le Québec, plutôt que d'engager le développement en silo d'une culture séparée.

Le film de Germain contient des éléments de la fatigue culturelle et montre toute l'ambiguïté du «groupe nationalitaire ». Premièrement, nous sommes encore devant la problématique de la préservation d'une culture qui se voit menacée par une structure opposante. Dans ce cas-ci comme dans les autres films, ce seraient à la fois la société canadienne et québécoise, tant au niveau institutionnel qu'au niveau culturel, qui présentent une menace, la première en raison de sa tendance à ethniciser les francophones et la seconde par son indifférence au sort des francophones hors Québec. Nous sommes néanmoins face à une tentative de réinscription dans le dialogue avec le Québec, contrairement aux autres films. L'enjeu tourne autour de la fête de la Saint-Jean Baptiste et Germain puise dans la mémoire du Canada français pour rappeler l'appartenance collective des Québécois et des Franco-Ontariens à une société 
proprement canadienne-française. En soi, cette réflexion n'est pas seulement le reflet d'un renouveau avec la question nationale, mais un moment de questionnement fort sur l'appartenance sociétale des Franco-Ontariens dans la famille canadienne-française après avoir navigué dans le creux de la vague pendant plusieurs années à tenter de formuler une autonomie sociétale sur le plan provincial.

\section{Conclusion : un cycle infatigable ?}

Est-ce que la fatigue culturelle est un cycle interminable pour le cinéma franco-ontarien ? Poser la question, c'est y répondre. Dans leurs efforts à «faire société », les Franco-Ontariens sont condamnés à une valse entre le Canada et le Québec qui, à tout moment, risque, tant en raison de leur propre incapacité que pour des raisons politiques, de les faire chuter vers l'ethnicisation. Toutefois, si le film de Germain est un quelconque indicateur de l'état de la question sociétale en Ontario français, les Franco-Ontariens tentent de franchir une étape importante : celle du renouveau dans le dialogue avec le Québec. Le problème de fond demeure néanmoins le même : entre la minorité nationale et la minorité ethnique, où se situent les FrancoOntariens ? La communauté demeure-t-elle «nationalitaire» comme le prétend Thériault dans «Entre la nation et l'ethnie »? Existe-t-il toujours une intention canadienne-française ou est-ce qu'il faut rompre avec cette mémoire (voir Thériault et Meunier) ? Entretemps, l'Ontario français semble voué à osciller entre deux pôles dans lesquels il ne peut pas ou ne veut pas entièrement s'intégrer.

\section{Euvres citées}

Aquin, Hubert. «La fatigue culturelle du Canada français [1962] ». La Révolution québécoise : Hubert Aquin et Gaston Miron au tournant des années 1960. Dir. Jean-Christian Pleau. Montréal : Fides, 2002. 197-233.

Bock, Michel. «De la "tradition" à la "participation" : les années 1960 et les mouvements de jeunesse franco-ontarien ». Cahiers Charlevoix: Études franco-ontariennes volume 8. Sudbury : Prise de parole, 2010. 111-196.

Dumont, Fernand. Genèse de la société québécoise. Montréal : Boréal, 1993.

Germain, Andréanne. Pis nous autres dans tout ça? Office national du film, 2009. Film.

Gratton, Michel. Montfort : La lutte d'un peuple. Ottawa : Centre franco-ontarien de ressources 
pédagogiques, 2003.

Hotte, Lucie. «Le Dernier des Franco-Ontariens: la rencontre entre un livre et un film». Francophonies d'Amérique 31 (2011) : 31-48.

Jacques, Daniel. «L'homme exorbité : réflexion sur la notion de fatigue culturelle chez Hubert Aquin ». Horizons politiques. 3.1 (1992) : 1-9.

Jaiko, Claudette. Deux voix comme en écho. Office national du film, 1987. Film.

Jaubert, Jean-Claude. «Le cinéma francophone canadien en situation minoritaire ». Toutes les photos finissent-elles par se ressembler? Actes du Forum sur la situation des arts au Canada français : forum de l'Institut franco-ontarien. Sudbury : Prise de parole, 1999 : 209-225.

---. «Des fées se penchent sur le berceau du cinéma ontarois ». Liaison (novembre 1990) : 2537.

Lapointe, Paul. J'ai besoin d'un nom. Office national du film, 1978. Film.

Larivière, Jean-Marc. Le Dernier des Franco-Ontariens. Office national du film, 1996. Film.

---. « Quand on aime le cinéma, on a toujours vingt ans ». Liaison (novembre 1994) : 20-30.

Thériault, Joseph Yvon. Faire société. Société civile et espaces francophones. Sudbury : Prise de parole, 2007.

---. «Entre la nation et l'ethnie : sociologie, société et communautés minoritaires francophones ». Sociologies et sociétés 26.1 (1994) : 15-32.

--- et E.-Martin Meunier. «Que reste-t-il de l'intention vitale du Canada français ?». L'espace francophone en milieu minoritaire au Canada: Nouveaux enjeux, nouvelles mobilisations. Dir. Joseph Yvon Thériault et al. Montréal : Fides, 2008. 205-238.

Truax, Denise. «Une année de cinéma, d'édition et de musique franco-ontarienne ». Liaison 3.10 (1980).

\footnotetext{
Notes

${ }^{1}$ Ce texte est une version remaniée d'un travail de maitrise dans le cadre du cours CDN 6520, «Séminaire sur la francophonie canadienne - Enjeux culturels contemporains » donné par Lucie Hotte à l'Université d'Ottawa en hiver 2010. Nous la remercions chaleureusement de ses commentaires judicieux dans la réfection de cet article. 2 Afin d'alléger la lecture de ce texte, toutes citations subséquentes, à moins d'avis contraire, sont tirées du film de Lapointe.

3 Afin d'alléger la lecture de ce texte, toutes citations subséquentes, à moins d'avis contraire, sont tirées du film de Jaiko.
} 
4 Afin d'alléger la lecture de ce texte, toutes citations subséquentes, à moins d'avis contraire, sont tirées de la retranscription du film de Larivière. De plus, le dernier des Franco-Ontariens s'écrit toujours avec un « $\mathrm{d}$ » majuscule dans ce document. Nous l'avons donc reproduit tel quel.

5 Afin d'alléger la lecture de ce texte, toutes citations subséquentes, à moins d'avis contraire, sont tirées du film de Germain. 